\title{
Proteomic analysis of human placental syncytiotrophoblast microvesicles in preeclampsia
}

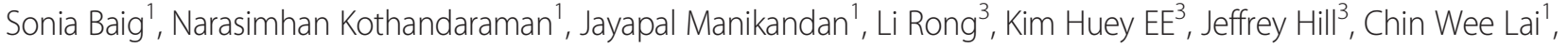

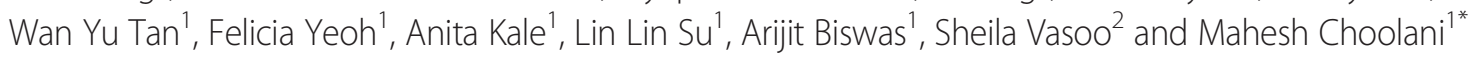

\begin{abstract}
Background: Placental syncytiotrophoblast microvesicles (STBM) are shed into the maternal circulation during normal pregnancy. STBM circulate in significantly increased amounts in preeclampsia (PE) and are considered to be among contributors to the exaggerated proinflammatory, procoagulant state of PE. However, protein composition of STBM in normal pregnancy and PE remains unknown. We therefore sought to determine the protein components of STBM and whether STBM protein expressions differ in preeclamptic and normal pregnancies.

Patients with PE $(n=3)$ and normal pregnant controls $(n=6)$ were recruited. STBM were prepared from placental explant culture supernatant. STBM proteins were analyzed by a combination of 1D Gel-LC-MS/MS. Protein expressions levels were quantified using spectral counts and validated by immunohistochemistry.

Results: Over 400 proteins were identified in the STBM samples. Among these, 25 proteins were found to be differentially expressed in preeclampsia compared to healthy pregnant controls, including integrins, annexins and histones.
\end{abstract}

Conclusion: STBM proteins include those that are implicated in immune response, coagulation, oxidative stress, apoptosis as well as lipid metabolism pathways. Differential protein expressions of STBM suggest their pathophysiological relevance in PE.

Keywords: Placental microvesicles, Pregnancy, Preeclampsia, Proteome

\section{Background}

Microvesicles and exosomes are small $(<1 \mu \mathrm{m})$ membranebound structures generated by cells after activation or apoptosis. They are important vehicles of intercellular communication carrying membrane, cytosolic and nuclear proteins, lipids, messenger RNAs and microRNAs [1-4]. Human placental syncytiotrophoblast microvesicles (STBM) are shed into the maternal circulation in normal pregnancy and are significantly increased in preeclampsia (PE) [5]. STBM are proinflammatory [6-8], procoagulant [9], and anti-angiogenic $[10,11]$ in normal pregnancy. Some of these characteristics are known to be exaggerated in (PE) $[9,10]$; however the

\footnotetext{
*Correspondence: obgmac@nus.edu.sg

'Division of Maternal-Fetal Medicine, Department of Obstetrics \&

Gynaecology, Yong Loo Lin School of Medicine, National University of Singapore \& National University Health System, 10 Medical Drive, Singapore 119260, Singapore

Full list of author information is available at the end of the article
}

basis of pathogenicity of preeclamptic STBM is yet to be elucidated.

Proteomes of microvesicles derived from platelets, plasma, malignant lymphocytes, endothelial cells, dendritic cells, mast cells, and intestinal epithelial cells have been published [12-18]. Broadly, microvesicle proteins are either ubiquitous or specific to cells of origin. Ubiquitous proteins are most likely involved in microvesicle biogenesis. Examples include tetraspanins (CD9, CD63, CD81 and CD82), heat shock proteins (HSP70, HSP90), cytoskeletal proteins (tubulin, actin, actin binding proteins), metabolic enzymes, membrane transport and fusion proteins (annexins and RAB proteins), signal transduction proteins (protein kinases, 14-3-3, G proteins), integrins and MHC class I and II molecules [19]. Examples of cell-specific proteins include MHC class II in exosomes from all cells expressing MHC class II, CD 86 from DC-derived exosomes (a co-stimulatory molecule for $\mathrm{T}$ cells), $\mathrm{T}$-cell receptors for $\mathrm{T}$-cell derived 
exosomes, and immunoglobulin family members (CD54 on B cells, P-selectin on platelets). In contrast to exosomes, microvesicles released by apoptotic cells do contain nuclear and organeller proteins, DNA, messenger and microRNA. Both exosomes and microvesicles may provide unconventional routes of protein secretion [20].

Multiple pathophysiologic factors are implicated in adverse pregnancy outcomes such as PE, including maternal immune maladaptation to the feto-placental unit, excessive fetal trophoblast apoptosis, and increased shedding of trophoblast debris. These result in increased systemic inflammatory response, haemostatic activation, endothelial dysfunction, and metabolic changes [21]. Defective trophoblast invasion resulting in abnormal uteroplacental perfusion and oxidative stress in PE may result in qualitative and subsequent functional changes in STBM. Quantitative changes in serum, placental and decidual lipid and protein oxidation products and anti-oxidant concentrations are significantly associated with PE [22]. Proteomic analyses of normal and PE placentas [23], syncytiotrophoblasts [24], cytotrophoblasts [25-27], deciduas [28], and plasmas [29,30] have been previously reported. While the role of placenta in PE is a vibrant area of research, the important question of why STBM from preeclamptic placenta may have proinflammatory and hypertensive effects on the maternal systemic vasculature remain unanswered. In particular, proteins of placental STBM in normal and preeclamptic pregnancy have not been determined yet.

We hypothesized that STBM proteins are differentially expressed in PE compared to normal pregnancies. Our objectives were to determine protein and peptide components of STBM that can incite pathogenic responses in pregnancy complications and explore whether these STBM protein expressions differ in pathologic (i.e., PE) and normal pregnancies. As opposed to earlier studies which employed 2D PAGE and MALDI TOF/TOF [23,31], and 2D DIGE [29], we used 1D Gel-LC-MS/MS approach to improve sensitivity [30]. Also, the current study aimed to investigate protein composition of placental microvesicles in health and disease which has not been reported to date.

\section{Results}

\section{Subject characteristics}

We studied 3 pregnant women complicated with PE and 6 healthy normal gestational age-matched pregnant women. The clinical characteristics of women and maternal and neonatal outcomes are summarized in Table 1. The patients underwent caesarean section or vaginal delivery at gestational age $>34$ weeks with live births.
Table 1 Maternal and fetal outcomes

\begin{tabular}{lll}
\hline & PE $(\mathbf{n}=\mathbf{3})$ & Normal controls $(\mathbf{n}=\mathbf{6})$ \\
\hline maternal age $(\mathrm{y})$ & $31 .[2.16]^{\mathrm{a}}$ & $36.33[5.28]$ \\
Gestational age $(\mathrm{w})$ & $36.09[0.95]$ & $36.38[1.56]$ \\
SBP $(\mathrm{mm} \mathrm{Hg})$ & $173.25[31]^{* * *}$ & $116.25[15.31]$ \\
DBP $(\mathrm{mm} \mathrm{Hg})$ & $109.5[13.2]^{* * *}$ & $76.5[5.58]$ \\
Proteinuria (g/24/h) & $1.14[0.57]$ & - \\
Infant birth wt $(\mathrm{g})$ & $2658[792.02]$ & $2722.5[434.79]$ \\
Placental wt $(\mathrm{g})$ & $508.33[79.74]$ & $526.80[94.17]$ \\
\hline
\end{tabular}

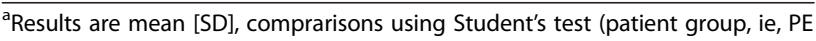
versus normal pregnant controls), $\mathrm{P}<0.0001^{* * *}$.

\section{STBM characterization}

STBM characterization data are summarized in Additional file 1: Figure S1. H/E and immunofluorescent (PLAP) staining of placental villous explants demonstrated the syncytiotrophoblast layer (Additional file 1: Figure S1- A \& B). Scanning electron microscopy demonstrated expected size of STBM (Additional file 1: Figure S1- C). Nanoparticle tracking analysis [32] showed STBM size distribution to be between $30-300 \mathrm{~nm}$ with a peak around $100 \mathrm{~nm}$ (Additional file 1: Figure S1- D).

\section{Identification of STBM proteins by 1D Gel-LC-MS/MS}

Representative 1D gels are shown in Figure 1. After ingel digestion, the tryptic peptides of each gel slice were analyzed by LC-MS/MS. Over 400 STBM proteins were identified (Additional file 2: Table S1). Proteins were designated as hits only when there were at least 2 unique peptides matches and Protein Identification Probability value of $>95 \%$. Spectral counts were used to quantify expression level of proteins in the whole lane.

Identification of differentially expressed STBM proteins in adverse pregnancies and healthy controls

We identified 25 STBM proteins to be differentially expressed between preeclamptic and normal pregnancies, listed in Table 2; notable among them are annexins, integrins, histones, heat shock proteins, complement regulatory proteins, cytoskeletal proteins, and various enzymes. Histones, integrins and CD59 glycoprotein were downregulated while the remaining were upregulated in preeclampsia. The Cellular components of STBM proteins are summarized in Additional file 3: Figure S2.

\section{Validation of proteomics results by immunohistochemistry (IHC) analysis}

IHC analysis of fixed and paraffin-embedded placental villous explants for validation of LC-MS/MS-based STBMproteomics data confirmed the presence of selected STBM proteins in the syncytiotrophoblast layer at periphery while negative controls showed no signals (Additional file 4: Table S2, Additional file 5: Figure S3). Statistically 


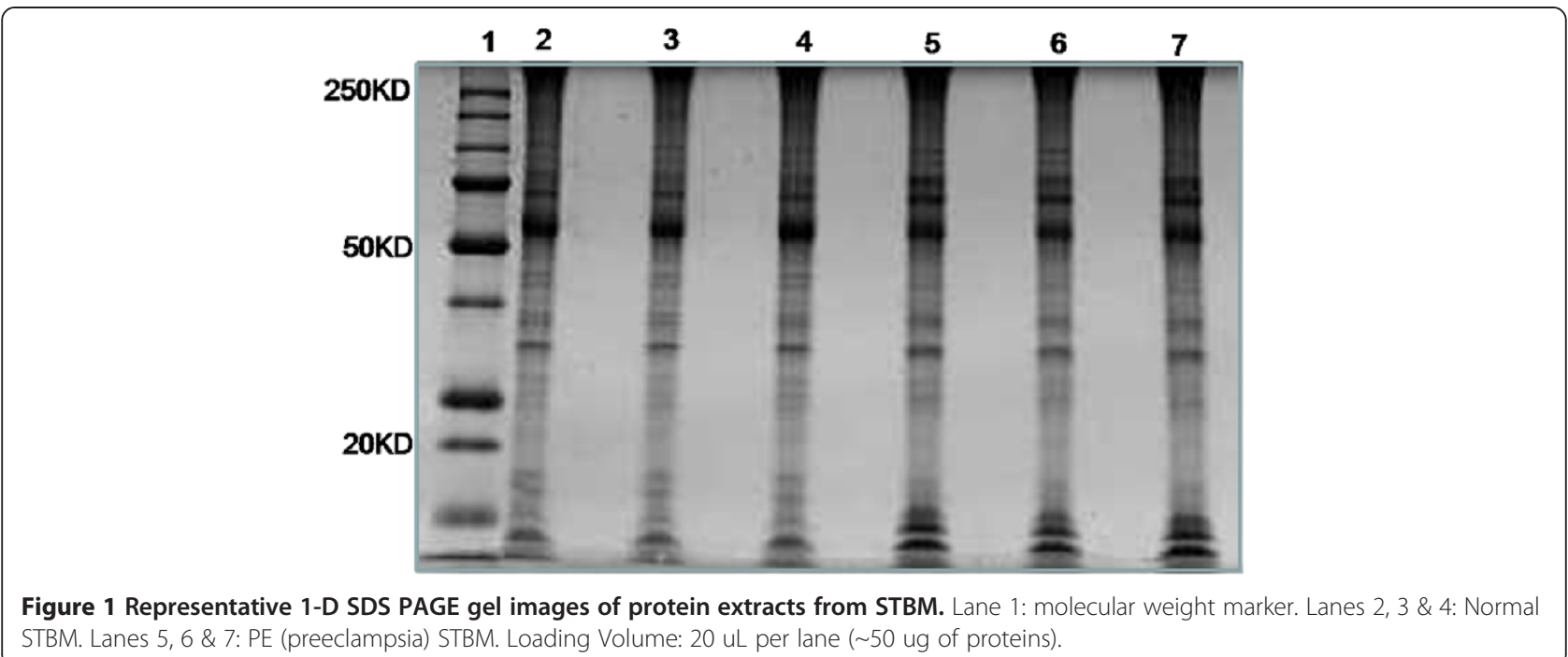

non-significant trends towards downregulation of these proteins, namely, histones, annexins, and integrins, could be observed (Additional file 6: Figure S4).

\section{Functional and pathway analysis}

Ingenuity Pathways Analysis (IPA) of statistically differentially expressed dataset containing 25 unique STBM proteins identified the significant biological functions and pathways. The major biological functions of STBM proteins include cell death and survival, cellular assembly and organization, immune response, lipid metabolism, and carbohydrate metabolism (Figure 2, Additional file 7: Table S3). The major canonical pathways include signaling associated with glycolysis, inter-cellular junctions, integrins, endothelial dysfunction (VEGF), immune response (NF-kB and complement system) and protein ubiquitination (Figure 2, Additional file 8: Table S4).

\section{Discussion}

We sought to determine the protein composition of STBM using 1D gel-LC-MS/MS approach to gain an insight into the pathophysiologic changes of PE. To our knowledge this study is the first report of STBM proteome in PE in comparison to that of normal healthy pregnancies.

Twenty five proteins were found to be differentially expressed between STBM derived from women with PE compared to healthy controls, including annexins, integrins, histones, and heat shock proteins. The annexins are calcium dependent-phospholipid binding proteins involved in various functions including signal transduction, stress response, inflammation, coagulation, apoptosis and lipid metabolism. Annexin A2 has been proposed to function inside the cell in sorting of endosomes and outside the cell in anticoagulant reactions [33]. The upregulation of anti-apoptosis proteins in PE STBM, such as annexin A4 (2-fold change, $\mathrm{p}<0.05)$ [34], can be explained by increased apoptotic activity of the placental syncytiotrophoblasts in $\mathrm{PE}$ which would trigger the generation of anti-apoptotic proteins in an attempt to counteract pro-inflammatory molecules such that homeostasis is achieved. Glyceraldehyde-3-phosphate dehydrogenase, a component of glycolytic pathway, has important functional relevance in anaerobic glycolysis in trophoblasts enriched in glycogen. Its increased expression in PE STBM (5-fold change, $\mathrm{p}<0.05$ ) could be associated with oxidative stress that exists in these adverse pregnancies [35,36]. Reduced expression of complement regulatory protein such as CD59 could be observed, suggestive of a possible role of STBM in hemostatic activation, as well as regulation [37]. Collectively all these protein expressions possibly depict the syncytiotrophoblast response at the maternal-fetal interface to underlying pregnancy pathology in PE.

Integrin signaling has an important role in trophoblast invasion and vasculature remodeling [38-40]. Its down regulation in PE STBM may be associated with shallow trophoblast invasion and defective placental vasculature in PE. Ezrin is involved in cell surface structure adhesion, migration and organization [41,42]. A trend towards increased expression of proteins such as 14-3-3 proteins, annexins and heat shock proteins may represent a protective response to tissue injury in pathologic pregnancies [43].

Major functions of histones include DNA binding, DNA repair and transcriptional regulation [44]. The unique finding of downregulation of histones in $\mathrm{PE}$ STBM, in this study ( 0.1 to 0.3 -fold change, $\mathrm{p}<0.05$ ), may be suggestive of defective DNA repair, increase in damaged DNA and raised inflammatory response in adverse pregnancies.

Interestingly, we found that STBM proteins include endogenous danger molecules or alarmins which may render 
Table 2 Differential protein expressions in STBM isolated from patients with PE $(n=3)$ versus that from pregnant controls $(n=6)$

\begin{tabular}{|c|c|c|c|c|c|c|c|c|}
\hline${ }^{\text {a Protein name }}$ & Symbol & $\begin{array}{l}\text { Accession } \\
\text { number }\end{array}$ & Molecular weight & ${ }^{\mathbf{b}}$ Mean PE & 'SEM PE & Mean NP & SEM NP & $p$-value \\
\hline isoform 1 of Annex in A2 & ANXA2 & IPI004553 15 & $39 \mathrm{kDa}$ & - & - & 66.32 & 16.12 & - \\
\hline isoform 2 of Annex in A2 & ANXA2 & IPI00418169 & $40 \mathrm{kDa}$ & 94.32 & 13.51 & - & - & - \\
\hline annex in A4 & ANXA4 & IPI00793199 & $36 \mathrm{kDa}$ & 109.78 & 24.56 & 47.36 & 9.72 & 0.0227 \\
\hline Histone H 14 & HST1HiE & IPI00217467 & $22 \mathrm{kDa}$ & - & - & 23.84 & 4.47 & - \\
\hline Histone 1.5 & HST1H1B & IPI00217468 & $23 \mathrm{kDa}$ & - & - & 6.56 & 169 & - \\
\hline Isoform 1 of Intergrin alpha-V & ITGAV & IPI00027505 & $116 \mathrm{kDa}$ & - & - & 25.60 & 4.02 & - \\
\hline Isoform Beta-1A of Intergrin beta-1 & ITGB 1 & IPI00217563 & $88 \mathrm{kDa}$ & 4.24 & 4.24 & 19.15 & 3.43 & 0.0353 \\
\hline Glyceraldehyde-3-phospahte dehydrogenase & GAPDH & IPI00219018 & $36 \mathrm{kDa}$ & 51.76 & 22.95 & 9.48 & 3.18 & 0.0312 \\
\hline Heat schock protein beta-1 & HSPB & IPI00025512 & $23 \mathrm{kDa}$ & 13.54 & 6.24 & 2.85 & 0.76 & 0.0398 \\
\hline Isoform 1 of Heat shock cognate 71 kDa protein & HSPA8 & IPI00003865 & $71 \mathrm{kDa}$ & 10.31 & 3.99 & 1.97 & 0.67 & 0.0202 \\
\hline 14-3-3 protein epsillon & YWHAE & IPI00000816 & $29 \mathrm{kDa}$ & 11.18 & 3.17 & - & - & - \\
\hline Actin, cytoplasmic 1 & ACTB & IPI00021439 & $42 \mathrm{kDa}$ & 35.21 & 13.53 & - & - & - \\
\hline ADP-ribosylation factor 1 & ARF 1 & IPI00215914 & $21 \mathrm{kDa}$ & 6.72 & 2.60 & - & - & - \\
\hline Alpha-actinin-1 & ACTN 1 & IPI00013508 & $103 \mathrm{kDa}$ & 21.58 & 1.97 & - & - & - \\
\hline CD59 glycoprotein & CD59 & IPI00011302 & $14 \mathrm{kDa}$ & - & - & 9.61 & 2.11 & - \\
\hline EF-hand domain-containing protein D1 & EFHD1 & IPI00031091 & $27 \mathrm{kDa}$ & 5.87 & 3.48 & - & - & - \\
\hline Ezrin & EZR & IPI00843975 & $69 \mathrm{kDa}$ & 40.30 & 15.01 & 1.17 & 0.98 & 0.0056 \\
\hline HSPA5 protein & HSPA 5 & IPI00003362 & $72 \mathrm{k} \mathrm{Da}$ & 10.80 & 3.96 & - & - & - \\
\hline Isoform 1 of Brain acid soluble protein 1 & BASP1 & IPI00299024 & $23 \mathrm{kDa}$ & 15.57 & 4.32 & 6.29 & 1.54 & 0.0373 \\
\hline Isoform alpha-enolase of Alpha-eno lase & EN01 & IPI00465248 & $47 \mathrm{kDa}$ & 12.22 & 6.22 & 1.96 & 0.69 & 0.0446 \\
\hline Isoform M2 of Pyruvate Kinase Isozymes MvM2 & PKM & IPI00479186 & $58 \mathrm{kDa}$ & 7.45 & 4.15 & - & - & - \\
\hline Transketo lase & TKT & IPI00643920 & $69 \mathrm{kDa}$ & 9.67 & 4.49 & 1.33 & 0.95 & 0.0374 \\
\hline Tubullin alpha- $1 \mathrm{C}$ cahin & TUBA $1 C$ & IPI00218343 & $50 \mathrm{kDa}$ & 10.24 & 4.47 & 0.33 & 0.33 & 0.0125 \\
\hline Tubullin beta- $2 \mathrm{C}$ cahin & TUBB4B & IPI00007752 & $50 \mathrm{kDa}$ & 5.98 & 3.10 & - & - & - \\
\hline${ }^{\mathrm{d}}$ Tubullin, beta & TUBB & IPI00645452 & $48 \mathrm{kDa}$ & 6.13 & 3.89 & - & - & - \\
\hline
\end{tabular}

${ }^{a}$ Only proteins with a fold change $>2$ or $<0.5$ and p-value $<0.05$ or expressed only in one group (either PE or NP) are listed.

${ }^{b}$ Numbers represent total spectral from all the peptides of a given protein.

${ }^{\mathrm{C}}$ Results are mean and standard error of mean (SEM), comparisons using $t$ test between patients with preciamsia (PE $n=3$ ) versus that from normal pregnant conrols (NP, $n=6)$.

${ }^{\mathrm{d}}$ For complete list of all STBM proteins see Additional file 4: Table S2 in Supplementary data.

them intensely pro-inflammatory such as extracellular free actins, tubulins, and heat shock proteins [3]. This supports the currently emerging role of STBM as contributors to the pro-inflammatory state of PE.

Future biomarker discovery work will include validation of biomarker potentials of differentially expressed proteins in patients' plasma. We acknowledge the limitations of using the label-free method and spectral counts in demonstrating the true representation of differential expression of low abundance proteins. Confirmation of the proteins found to be differentially expressed in this study needs to be carried out with isotope-encoded peptides corresponding to the tryptic peptides of the selected proteins. This will help determine absolute concentration of targeted proteins.

\section{Conclusions}

The present study suggests that the biological pathways associated with PE may include immune response, coagulation, endothelial dysfunction as well as lipid metabolism. We have recently reported differential lipid expressions in STBM from the same cohort of patients [45]. While previous evidence for increased activation of hemostasis and endothelial dysfunction exists, the concept and proposed roles of immune-dysregulation and lipid metabolism in pathophysiology of adverse pregnancies are novel and yet to be established. Our findings are consistent with recent reports on PE pregnancy sera $[29,30]$, demonstrating pro-inflammatory and lipidregulatory protein expressions, besides those involved in hemostasis and endothelial dysfunction. Targeting these 


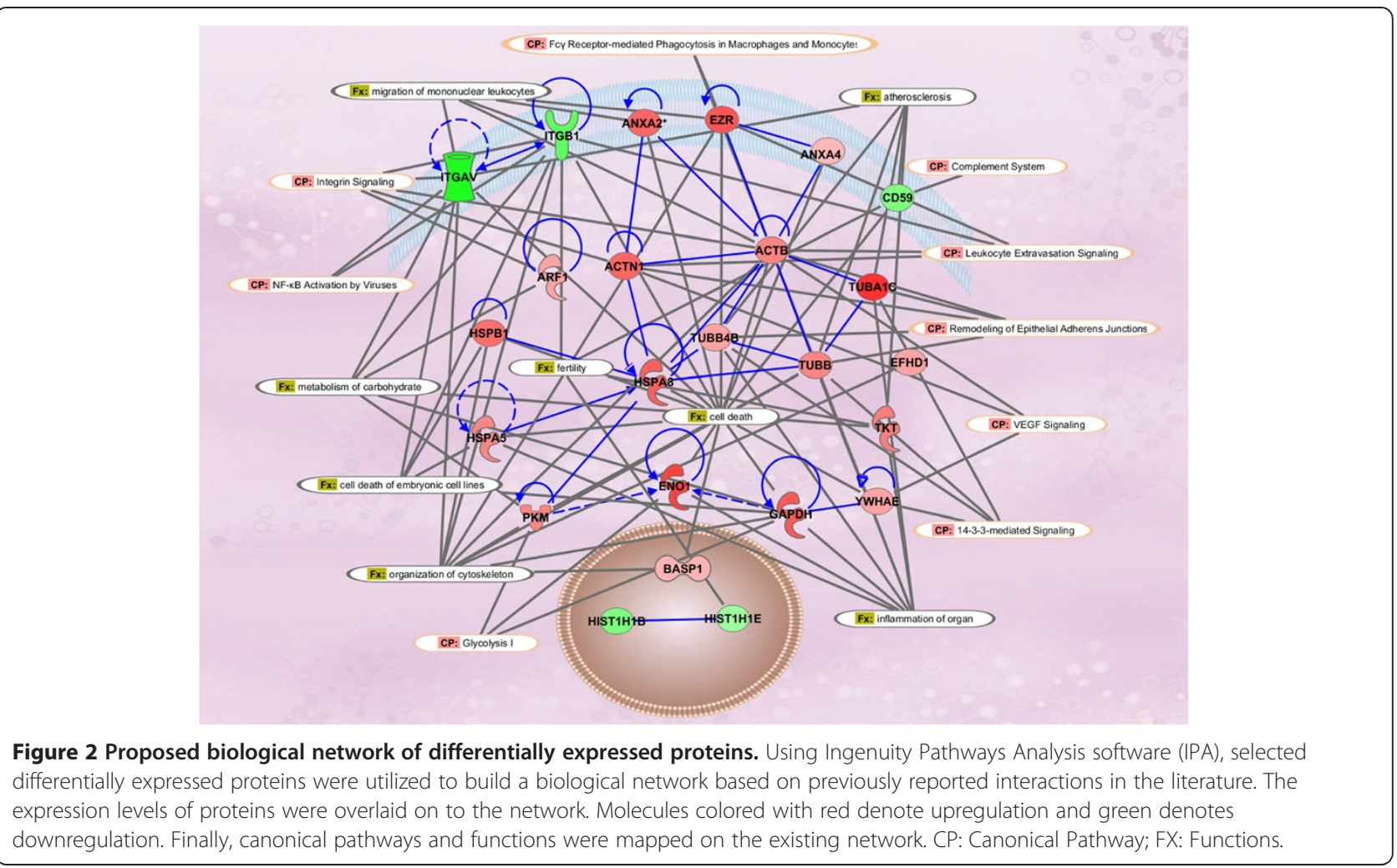

novel pathways may offer newer strategies of management of adverse pregnancies.

\section{Methods}

\section{Subjects and sample collection}

The study subjects were patients with PE. PE was defined as increased blood pressure $(\geq 140 / 90 \mathrm{~mm} \mathrm{Hg})$ that occurred after 20 wks of gestation in previously normotensive women accompanied with proteinuria of $\geq 0.3 \mathrm{~g} /$ day. The controls were gestational age-matched (within 2 gestational weeks) healthy subjects with no pregnancy complications. Placental samples were collected at the time of delivery and processed within 2 hours. All samples were collected from the National University Hospital affiliated to the National University of Singapore, Singapore. The research protocol was approved by the Domain Specific Review Board.

\subsection{Placental microvesicle (STBM) preparation and characterization}

Placental villous tissue ( $2 \mathrm{gm})$ was cut into small pieces (2-4) $\mathrm{mm}^{3}$ and rinsed in PBS until blood less. Explants were cultured in $100 \mathrm{~mm}$ culture dishes in DMEM-F12 culture medium, supplemented with $1 \%$ antimycotic/antibiotics and $10 \%$ heat-inactivated fetal bovine serum, for generation of STBM at $37^{\circ} \mathrm{C}$ in $8 \%$ oxygen in the hypoxic incubator (Galaxy 48R $\mathrm{CO}_{2}$ incubator with $\mathrm{O}_{2}$ control 0.1 to $19 \%$ range). Prior to addition to the culture media, the heat-inactivated fetal bovine serum was centrifuged at $100000 \mathrm{~g}$ for $60 \mathrm{~min}$ for removal of microvesicles in serum. At the end of 72 hours culture period, the supernatant was collected followed by differential centrifugation for isolation of STBM.

Culture supernatant was subjected to a three-step centrifugation at $4^{\circ} \mathrm{C}-1000 \mathrm{~g}$ for $10 \mathrm{~min}$ (separation of whole cells), 10,000 g for $10 \mathrm{~min}$ (separation of large cellular organelles, such as mitochondria, golgi, ER, etc.) and finally, $100000 \mathrm{~g}$ for $60 \mathrm{~min}$ (for collecting subcellular membrane microvesicles). The final pellet was collected, washed in sterile PBS and resuspended in $0.5 \mathrm{ml}$ sterile PBS and stored at $-20^{\circ} \mathrm{C}$ until use. The protein content in each STBM preparation was quantified with Bradford assay (Pierce, Rockford, IL). Typical STBM preparations yielded $0.2-0.4 \mathrm{mg} / \mathrm{ml}$ vesicles. STBM size and number in sample was determined by Nanoparticle Tracking Analysis (NTA) method (Dragovic et al. [32]). Finally STBM samples were subjected to evaluation scanning electron microscopy (SEM). Additional $48 \mathrm{hr}$ culture of aliquots of explant culture supernatants was carried out prior to STBM isolation to confirm the absence of bacterial growth and endotoxin contamination.

Protein separation, in-gel digestion and LC-MS/MS analysis The STBM samples prepared from placental explant culture supernatant were pelleted down. STBM pellets were then resuspended in RIPA lysis buffer (Pierce, Rockford, 
IL), homogenized by vortexing and lysed on ice for 30 minutes. The sample was centrifuged at $14,000 \mathrm{~g}$ for 15 minutes at $4^{\circ} \mathrm{C}$ and the supernatant (lysate) was collected.

The protein lysate derived from the STBM was then subjected to precipitation overnight at $-20^{\circ} \mathrm{C}$ after addition of five volumes of pre-cooled acetone. Protein precipitation was followed by reduction with $10 \mathrm{mM}$ dithiothreitol (DTT) and alkylation with $20 \mathrm{mM}$ iodoacetamide (IAA). The protein content in each STBM preparation was quantified with Bradford assay (Pierce, Rockford, IL). Proteins $(\sim 50 \mu \mathrm{g})$ were separated on a 10.5-14\% Tris-HCl SDS-gel (BIO-RAD) and stained with PageBlue ${ }^{\mathrm{Tx}}$ protein staining solution (Fermentas) containing Coomassie Brilliant Blue G-250 dye. 1D SDSPAGE system (BIO-RAD) was used to separate the protein lysate derived from STBM.

Each lane in gel was finely cut into 13 slices, transferred into a 96 wells plate with hole and in-gel digestion was performed as follows. First, destaining was performed by the addition of $100 \mathrm{ul}$ of $100 \mathrm{mM}$ TEAB/ $\mathrm{EtOH}(1: 1, \mathrm{vol} / \mathrm{vol})$ and incubated with occasional vortexing for $60 \mathrm{~min}$ at $56^{\circ} \mathrm{C}$, followed by addition of $100 \mathrm{ul}$ of neat acetonitrile and incubation at room temperature with occasional vortexing, until gel pieces became white and dried. Then acetonitrile was removed. Buffer containing trypsin $(20 \mathrm{ng} / \mathrm{ul})$ was added in an amount to cover the dry gel pieces (typically, 50 ul or more, depending on the volume of a gel matrix) and left in an ice bucket or a fridge about $15 \mathrm{~min}$. After $15 \mathrm{~min}$, it was checked if all solution was absorbed and more trypsin containing buffer was added, if necessary. After full rehydration the remaining trypsin buffer was spun out, then $10-20 \mathrm{ul}$ of $10 \mathrm{mM}$ TEAB buffer was added to cover the gel pieces and keep them wet during enzymatic cleavage. Plate with gel pieces was placed into an air circulation thermostat and samples were incubated overnight at $37^{\circ} \mathrm{C}$. Plate was chilled to room temperature and $5 \mathrm{ul} 5 \%$ formic acid (FA) was added to stop digestion. Solution was spun down into new 96 wells collection plate using a plate centrifuge followed by addition of $50 \mathrm{ul}$ 1\%FA twice and $50 \mathrm{ul}$ of $1: 2(\mathrm{vol} / \mathrm{vol}) \quad 0.1 \%$ formic acid/acetonitrile to extract peptide from gel. $300 \mathrm{ul} \mathrm{ali-}$ quots of the supernatant directly from the digest extracted from the gel pieces was used for the subsequent MS/MS analysis. Samples were freeze-dried and the dried protein film was then reconstituted in formic acid prior to analysis by mass spectrometry.

For LC MS/MS analysis, $10 \mathrm{ul} \mathrm{of} 0.1 \%$ (vol/vol) formic acid was added into each well to resuspend peptides. 5 ul sample was injected to Agilent 6538 chip LCMSMS system for analysis after separation by Agilent 1200 LC system, using a 1D nano -LC setup consisting of a capillary pump for loading the sample (operated at $4 \mathrm{uL} / \mathrm{min}$ ) onto 1.0-cm trap column and a nano pump (operated at $300 \mathrm{~nL} / \mathrm{min}$ ) for the separation on the analytical column. $100 \%$ water with $0.1 \%$ formic acid was used as solvent $\mathrm{A}$ and $100 \%$ Acetonitrile with $0.1 \%$ formic acid was used as solvent $\mathrm{B}$. The peptides were eluted from the precolumn using a gradient from $95 \%$ phase A $(0.1 \%$ FA aqueous solution) to $45 \%$ phase B $(0.1 \% \mathrm{FA}, 100 \%$ acetonitrile $)$ in $60 \mathrm{~min}$ at $300 \mathrm{nl} / \mathrm{min}$ directly onto an analytical column (50-um inner diameter, 360-um outer diameter, ReproSilPur C18 5um). The instrument was operated in a datadependent mode automatically switching between MS, MS2. Acquisition was set to automatically select and further fragment the fragment ion originating from the loss of phosphoric acid from the parent ions (standard pdMS2 settings).

\section{LC-MS/MS data processing and quantitative analysis}

Generated mass spectral data were analyzed using Mascot sequence matching software (Matrix Science). General search parameters used were: Enzyme, Trypsin; Maximum of 2 missed cleavages; Fixed modifications, Carbamidomethyl (C); Variable modifications, Oxidation (M), Deamidated (NQ), Phospho (STY), Acetyl (K); Peptide tolerance range $\pm 100 \mathrm{ppm}$; and MS/MS tolerance range, $\pm 0.6 \mathrm{Da}$. Data import filters used were Mascot Distiller (Matrix Science). Analyzed database-search results (.dat) from Mascot were uploaded onto Scaffold interface. Result files were categorized and named according to sample type or nature. Multidimensional protein identification technology (MuDPIT) experiment and condensation of loaded data were selected. Proteins were designated as hits only when there were at least 2 unique peptides matches and Protein Identification Probability value of $>95 \%$.

The quantitation of protein expressions by spectral counts for each identified proteins (defined as total spectral counts for all the peptides of a given protein) was carried out using Scaffold program (Proteome Software, version 4). Only proteins with spectral counts $\geq 5$ and a ratio of spectral counts between two groups (patients and normal controls) of $>2$ or $<0.5$ were tested further by $t$-test and validation by immunohistochemistry.

\section{Immunohistochemistry (IHC)}

Villous explants were fixed and paraffin-embedded. Tissue microarrays were prepared. IHC was performed according to manufacturer's instructions (Leica Microsystems). Briefly, after deparaffinization and heat-induced epitope retrieval, endogenous peroxidase blocking was performed. Slides were incubated with primary antibodies for 45 minutes. Antibodies used are listed in Additional file 2: Table S1. After washing, the sections were exposed to anti-rabbit poly-HRP-IgG in $10 \%$ animal serum for 10 minutes, followed by $\mathrm{DAB}$ reagents for 3 minutes. $\mathrm{DAB}$ reaction was stopped, and counterstaining with hematoxylin was 
performed for 5 minutes. After washing, sections were dehydrated and finally mounted in synthetic mounting media (Electron Microscopy Services, Hatfield, USA). Controls included omission of primary antibodies. After IHC, tissue microarray slides were scanned, analyzed and scored (Leica Microsystems slide scanner and Slidepath image analysis software).

\section{Functional and pathway analysis}

To define biological networks, interaction and functional analysis among the differentially expressed proteins, pathway analyses were performed using Ingenuity Pathways Analysis software (IPA) (Ingenuity Systems, Redwood City, CA). Statistically differentially expressed dataset containing 25 unique proteins and their corresponding IPI identifier, p-value and fold change values were uploaded into the IPA. The significance of the connection between the expression data and the canonical pathway were calculated by ratio and/or Fisher's exact.

\section{Statistical analysis}

Analysis of statistical significance of differences in protein spectral counts between patient group and normal healthy pregnant group were sought using Student's two-tailed unpaired $t$-test. Analyzes were performed using GraphPad Prism 5 software. Results were considered to be statistically significant if $p<0.05$.

\section{Supplementary information}

Supplementary Information includes four supplementary tables and four supplementary figures and can be found with this article online.

\section{Additional files}

Additional file 1: Figure S1. Representative images of STBM basic characterization. A. H/E staining of placental villous explants showing deep blue syncytiotrophoblast (STB) layer at periphery (X20); B. Immunofluorescence (IF) image of placental villous explants demonstrating the bright green layer of STB stained for Placental Alkaline Phosphatase, PLAP (X40); C. Representative scanning electron microscopy image of STBM by (X10.000); D. Representative light scatter of STBM by nanoparticle tracking analysis (NTA), showing STBM size to be between 30-300 nm with a peak around $100 \mathrm{~nm}$

Additional file 2: Table S1. Antibodies used for Immunohistochemistry Additional file 3: Figure S2. Cellular components of STBM proteins. The placental membrane microvesicles, ie, STBM carry membrane, cytoskeletal and regulatory proteins.

Additional file 4: Table S2. List of STBM proteins.

Additional file 5: Figure S3. Representative Immunohistochemistry images of formalin-fixed paraffin-embedded placental villous explants from women with preeclampsia (PE) and normal healthy pregnancy. Proteins are localized in the syncytiotrophoblasts. Bars represent $100 \mu \mathrm{m}$ (original magnification X200)

Additional file 6: Figure S4. Summary of Immunohistochemical validation of PE STBM protein expressions. Comparison of mean staining intensity units of individual proteins in STBM from PE patients $(n=3)$ and normal pregnant women $(n=6)$.

Additional file 7: Table S3. Functional analysis of the differentially regulated proteins.

Additional file 8: Table S4. Canonical pathways predicted by Ingenuity Pathway Analysis.

\section{Abbreviations}

STBM: Syncytiotrophoblast microvesicle; PE: Preeclampsia; PLAP: Placental alkaline phosphatase; NTA: Nanoparticle tracking analysis.

\section{Competing interests}

The authors declare that they have no competing interests.

\section{Authors' contributions}

SB contributed to study concept and design, acquisition of data, analysis and interpretation of data, drafting of the manuscript, critical revision of the manuscript for important intellectual content, statistical analysis and obtaining funding. $\mathrm{NK}, \mathrm{JM}, \mathrm{RL}, \mathrm{KH}$ and $\mathrm{JH}$ participated in acquisition of data, analysis and interpretation of data, and critical revision of the manuscript for important intellectual content. CL, WT and FY participated in acquisition of data, analysis and interpretation of data, and statistical analysis. AK, LS and $A B$ contributed to study concept and design, selection and enrollment of patients, and obtaining funding. SV and MC contributed to study concept and design, selection and enrollment of patients, acquisition of data, analysis and interpretation of data, critical revision of the manuscript for important intellectual content, and obtaining funding. All authors read and approved the final manuscript.

\section{Acknowledgements}

This research was funded by National Medical Research Council grants (NMRC/NIG/1022/2010) and (NMRC/CSA/007/2009). We would like to thank Ms Cecille Arquillo Laureano, the staff and patients of delivery suite, Women's clinic and ward of the National University Health System for their help in obtaining research samples. We would also like to thank Mr Keith Rogers \& Dr Adam Cliffe, Institute of Molecular \& Cell Biology, Agency for Science, Technology and Research, for support in immunohistochemistry analysis.

\section{Author details}

'Division of Maternal-Fetal Medicine, Department of Obstetrics \& Gynaecology, Yong Loo Lin School of Medicine, National University of Singapore \& National University Health System, 10 Medical Drive, Singapore 119260, Singapore. ${ }^{2}$ Division of Rheumatology, Department of Medicine, Yong Loo Lin School of Medicine, National University of Singapore \& National University Health System, 10 Medical Drive, Singapore 119260, Singapore. ${ }^{3}$ Experimental Therapeutic Center, Agency for Science, Technology and Research, 31 Biopolis Way, Singapore 138669, Singapore.

Received: 22 January 2014 Accepted: 29 October 2014 Published: 19 November 2014

\section{References}

1. Gupta AK, Holzgreve W, Hahn S: Decrease in lipid levels of syncytiotrophoblast micro- particles reduced their potential to inhibit endothelial cell proliferation. Arch Gynecol Obstet 2008, 277:115-119.

2. Cocucci E, Racchetti G, Meldolesi J: Shedding microvesicles: artefacts no more. Trends Cell Biol 2009, 19:43-51.

3. Redman CW, Tannetta DS, Dragovic RA, Gardiner C, Southcombe JH, Collett GP, Sargent IL: Review: does size matter? Placental debris and the pathophysiology of pre-eclampsia. Placenta 2012, 33(Suppl):S48-S54.

4. Rajakumar A, Cerdeira AS, Rana S, Zsengeller Z, Edmunds L, Jeyabalan A, Hubel CA, Stillman IE, Parikh SM, Karumanchi SA: Transcriptionally active syncytial aggregates in the maternal circulation may contribute to circulating soluble fms-like tyrosine kinase 1 in preeclampsia. Hypertension 2012, 59:256-264.

5. Knight M, Redman CW, Linton EA, Sargent IL: Shedding of syncytiotrophoblast microvilli into the maternal circulation in pre-eclamptic pregnancies. $\mathrm{Br} J$ Obstet Gynaecol 1998, 105:632-640. 
6. Germain SJ, Sacks GP, Sooranna SR, Sargent IL, Redman CW: Systemic inflammatory priming in normal pregnancy and preeclampsia: the role of circulating syncytiotrophoblast microparticles. J Immunol 2007 178:5949-5956.

7. Messerli M, May K, Hansson SR, Schneider H, Holzgreve W, Hahn S, Rusterholz C: Feto-maternal interactions in pregnancies: placental microparticles activate peripheral blood monocytes. Placenta 2009, 31:106-112.

8. Southcombe J, Tannetta D, Redman C, Sargent I: The immunomodulatory role of syncytiotrophoblast microvesicles. PLoS One 2011, 6:e20245.

9. Gardiner C, Tannetta DS, Simms CA, Harrison P, Redman CW, Sargent IL: Syncytiotrophoblast microvesicles released from pre-eclampsia placentae exhibit increased tissue factor activity. PLoS One 2011, 6:e26313.

10. Smarason AK, Sargent IL, Starkey PM, Redman CW: The effect of placental syncytiotrophoblast microvillous membranes from normal and pre-eclamptic women on the growth of endothelial cells in vitro. Br J Obstet Gynaecol 1993, 100:943-949.

11. Gupta AK, Rusterholz C, Holzgreve W, Hahn S: Syncytiotrophoblast microparticles do not induce apoptosis in peripheral T lymphocytes, but differ in their activity depending on the mode of preparation. J Reprod Immunol 2005, 68:15-26.

12. Garcia BA, Smalley DM, Cho H, Shabanowitz J, Ley K, Hunt DF: The platelet microparticle proteome. J Proteome Res 2005, 4:1516-1521.

13. Jin M, Drwal G, Bourgeois T, Saltz J, Wu HM: Distinct proteome features of plasma microparticles. Proteomics 2005, 5:1940-1952.

14. Miguet L, Pacaud K, Felden C, Hugel B, Martinez MC, Freyssinet JM, Herbrecht R, Potier N, van Dorsselaer A, Mauvieux L: Proteomic analysis of malignant lymphocyte membrane microparticles using double ionization coverage optimization. Proteomics 2006, 6:153-171.

15. Wubbolts R, Leckie RS, Veenhuizen PT, Schwarzmann G, Mobius W, Hoernschemeyer J, Slot JW, Geuze HJ, Stoorvogel W: Proteomic and biochemical analyses of human B cell-derived exosomes. Potentia implications for their function and multivesicular body formation. J Biol Chem 2003, 278:10963-10972.

16. Thery C, Regnault A, Garin J, Wolfers J, Zitvogel L, Ricciardi-Castagnoli P, Raposo G, Amigorena S: Molecular characterization of dendritic cellderived exosomes. Selective accumulation of the heat shock protein hsc73. J Cell Biol 1999, 147:599-610.

17. Thery C, Boussac M, Veron P, Ricciardi-Castagnoli P, Raposo G, Garin J, Amigorena S: Proteomic analysis of dendritic cell-derived exosomes: a secreted subcellular compartment distinct from apoptotic vesicles. $\mathrm{J}$ Immunol 2001, 166:7309-7318.

18. van Niel G, Raposo G, Candalh C, Boussac M, Hershberg R, Cerf-Bensussan $\mathrm{N}$, Heyman M: Intestinal epithelial cells secrete exosome-like vesicles. Gastroenterology 2001, 121:337-349.

19. Thery C, Zitvogel L, Amigorena S: Exosomes: composition, biogenesis and function. Nat Rev Immunol 2002, 2:569-579.

20. Nickel W: Unconventional secretory routes: direct protein export across the plasma membrane of mammalian cells. Traffic 2005, 6:607-614.

21. Roberts JM, Lain KY: Recent Insights into the pathogenesis of pre-eclampsia. Placenta 2002, 23:359-372.

22. Serdar Z, Gur E, Colakoethullary M, Develioethlu O, Sarandol E: Lipid and protein oxidation and antioxidant function in women with mild and severe preeclampsia. Arch Gynecol Obstet 2003, 268:19-25.

23. Gharesi-Fard B, Zolghadri J, Kamali-Sarvestani E: Proteome differences of placenta between pre-eclampsia and normal pregnancy. Placenta 2009, 31:121-125.

24. Okamura K, Powell JE, Lee AC, Stevens VC: Characterization of solubilized microvillous membrane proteins and glycoproteins from human placental syncytiotrophoblast. Placenta 1981, 2:117-128.

25. Hu R, Jin H, Zhou S, Yang P, Li X: Proteomic analysis of hypoxia-induced responses in the syncytialization of human placental cell line BeWo. Placenta 2007, 28:399-407.

26. Johnstone ED, Sawicki G, Guilbert L, Winkler-Lowen B, Cadete VJ, Morrish DW: Differential proteomic analysis of highly purified placental cytotrophoblasts in pre-eclampsia demonstrates a state of increased oxidative stress and reduced cytotrophoblast antioxidant defense. Proteomics 2011, 11:4077-4084.

27. Epiney M, Ribaux $\mathrm{P}$, Arboit $\mathrm{P}$, Irion $\mathrm{O}$, Cohen $\mathrm{O}$ : Comparative analysis of secreted proteins from normal and preeclamptic trophoblastic cells using proteomic approaches. J Proteomics 2012, 75:1771-1777.
28. Menkhorst EM, Lane N, Winship AL, Li P, Yap J, Meehan K, Rainczuk A, Stephens A, Dimitriadis E: Decidual secreted factors alter invasive trophoblast membrane and secreted proteins implying a role for decidual cell regulation of placentation. PLoS One 2012, 7:e31418.

29. Blumenstein M, McMaster MT, Black MA, Wu S, Prakash R, Cooney J, McCowan LM, Cooper GJ, North RA: A proteomic approach identifies early pregnancy biomarkers for preeclampsia: novel linkages between a predisposition to preeclampsia and cardiovascular disease. Proteomics 2009, 9:2929-2945.

30. Liu C, Zhang N, Yu H, Chen Y, Liang Y, Deng H, Zhang Z: Proteomic analysis of human serum for finding pathogenic factors and potential biomarkers in preeclampsia. Placenta 2010, 32:168-174.

31. Shin JK, Baek JC, Kang MY, Park JK, Lee SA, Lee JH, Choi WS, Paik WY: Proteomic analysis reveals an elevated expression of heat shock protein 27 in preeclamptic placentas. Gynecol Obstet Invest 2011, 71:151-157.

32. Dragovic RA, Gardiner C, Brooks AS, Tannetta DS, Ferguson DJ, Hole P, Carr B, Redman CW, Harris AL, Dobson PJ, Harrison P, Sargent IL: Sizing and phenotyping of cellular vesicles using Nanoparticle Tracking Analysis. Nanomedicine 2011, 7:780-788.

33. Takahashi S, Reddy SV, Chirgwin JM, Devlin R, Haipek C, Anderson J, Roodman GD: Cloning and identification of annexin II as an autocrine/ paracrine factor that increases osteoclast formation and bone resorption. J Biol Chem 1994, 269:28696-28701.

34. El Kebir D, Jozsef L, Filep JG: Opposing regulation of neutrophil apoptosis through the formyl peptide receptor-like 1/lipoxin A4 receptor: implications for resolution of inflammation. J Leukoc Biol 2008, 84:600-606.

35. Tarze A, Deniaud A, Le Bras M, Maillier E, Molle D, Larochette N, Zamzami N, Jan G, Kroemer G, Brenner C: GAPDH, a novel regulator of the pro-apoptotic mitochondrial membrane permeabilization. Oncogene 2007, 26:2606-2620.

36. Zala D, Hinckelmann MV, Yu H, da Cunha MM L, Liot G, Cordelières FP, Marco S, Saudou F: Vesicular glycolysis provides on-board energy for fast axonal transport. Cell 2013, 152:479-491.

37. Huang Y, Qiao F, Abagyan R, Hazard S, Tomlinson S: Defining the CD59-C9 binding interaction. J Biol Chem 2006, 281:27398-27404.

38. Murai JT, Muzykanskiy E, Taylor RN: Maternal and fetal modulators of lipid metabolism correlate with the development of preeclampsia. Metabolism 1997, 46:963-967.

39. Redfern CH, Degtyarev MY, Kwa AT, Salomonis N, Cotte N, Nanevicz T, Fidelman N, Desai K, Vranizan K, Lee EK, Coward P, Shah N, Warrington JA, Fishman Gl, Bernstein D, Baker AJ, Conklin BR: Conditional expression of a $\mathrm{Gi}$-coupled receptor causes ventricular conduction delay and a lethal cardiomyopathy. Proc Natl Acad Sci U S A 2000, 97:4826-4831.

40. Huppertz B, Berghold VM, Kawaguchi R, Gauster M: A variety of opportunities for immune interactions during trophoblast development and invasion. Am J Reprod Immunol 2012, 67:349-357.

41. Granés F, Urena JM, Rocamora N, Vilaró S: Ezrin links syndecan-2 to the cytoskeleton. J Cell Sci 2000, 113:1267-1276.

42. Yun $\mathrm{CH}$, Lamprecht G, Forster DV, Sidor A: NHE3 kinase A regulatory protein E3KARP binds the epithelial brush border $\mathrm{Na}+/ \mathrm{H}+$ exchanger NHE3 and the cytoskeletal protein ezrin. J Biol Chem 1998, 273:25856-25863.

43. Benoit C, Zavecz J, Wang Y: Vasoreactivity of chorionic plate arteries in response to vasoconstrictors produced by preeclamptic placentas. Placenta 2007, 28:498-504.

44. Liang D, Burkhart SL, Singh RK, Kabbaj MH, Gunjan A: Histone dosage regulates DNA damage sensitivity in a checkpoint-independent manner by the homologous recombination pathway. Nucleic Acids Res 2012, 40:9604-9620.

45. Baig S, Lim JY, Fernandis AZ, Wenk MR, Kale A, Su LL, Biswas A, Vasoo S, Shui G, Choolani M: Lipidomic analysis of human placental Syncytiotrophoblast microvesicles in adverse pregnancy outcomes. Placenta 2013, 34:436-442.

doi:10.1186/1559-0275-11-40

Cite this article as: Baig et al:: Proteomic analysis of human placental syncytiotrophoblast microvesicles in preeclampsia. Clinical Proteomics 2014 11:40 